\title{
Hematoma espontáneo paracavernoso
}

\author{
Martínez-Rodríguez RH, Gutiérrez-Ruiz C, Rodríguez-Escovar F, Angerri O, Sarquella Geli J, \\ Villavicencio Mavrich $\mathrm{H}$.
}

Servicio de Urología. Fundación Puigvert. Barcelona.

Actas Urol Esp. 2007;31(7):781-782

\section{RESUMEN}

HEMATOMA ESPONTANEO PARA CAVERNOSO

Se presenta un caso de hematoma perineal de disposición fusiforme, dependiente de los cuerpos cavernosos pero con integridad de los mismos, sin repercusión sobre la capacidad eréctil y sin antecedente causal conocido. Etiopatología, diagnóstico y tratamiento son analizados.

Palabras clave: Cuerpos cavernosos. Hematoma. Lesión espontánea.

\section{ABSTRACT}

\section{SPONTANEUOS HAEMATOMA FOR PARACAVERNOSO}

We report a case of spontaneous, perineal haematoma depending on corpora cavernosa but without injury of them. No erectile dysfunction was associated. Not traumatic injury was known. Etiopathology, diagnosis and treatment are analyses.

Keywords: Corpora cavernosa. Haematoma. Spontaneuos injury.

$\mathrm{L}^{2}$ a aparición de hematomas perineales suele asociar compromiso de cuerpos cavernosos y presenta antecedente traumático en casi la totalidad de los casos publicados. Durante la erección, la túnica albugínea disminuye su espesor (de $2 \mathrm{~mm}$ en flacidez a 0,5-0,25 $\mathrm{mm}$ en erección) haciéndola más vulnerable a los traumatismos externos ${ }^{1,2}$. La prevalencia de fracturas de cuerpos cavernosos por traumatismos sobre el pene flácido es de un $3 \%^{2}$.

No se ha encontrado ningún caso publicado en referencia a hematoma espontáneo, sin antecedente traumático conocido, sin repercusión sobre la capacidad eréctil y asintomático salvo la tumefacción local.

\section{CASO CLINICO}

Varón de 46 años de edad, sin antecedentes patológicos de interés salvo vasectomía a los 42 años, que acudió al servicio de urgencias por tumoración perineal de inicio insidioso y aumen- to progresivo del tamaño en los últimos días, sin repercusión sobre la capacidad eréctil ni la micción. Negaba rotundamente antecedente traumático. A la exploración presentaba tumoración perineal de localización paracavernosa izquierda, no fluctuante, no dolorosa, de consistencia fibroelástica.

Se realizó ecografía de partes blandas con orientación diagnóstica hacia hematoma perineal dependiente de porción proximal de cuerpo cavernoso izquierdo.

En la Resonancia Magnética Nuclear se describía área hipointensa de aproximadamente $8 \times 2 \times 0,8 \mathrm{~cm}$. localizada en región posterior de cuerpo cavernoso izquierdo con integridad de túnica albuginea y fascia de Buck (Figs. 1 y 2).

Se realizó estudio bacteriológico de material obtenido mediante punción con cultivo negativo.

Se instauró tratamiento antiagregante vía oral y medidas físicas presentando reabsorción del hematoma y resolución completa a los 4 meses. 

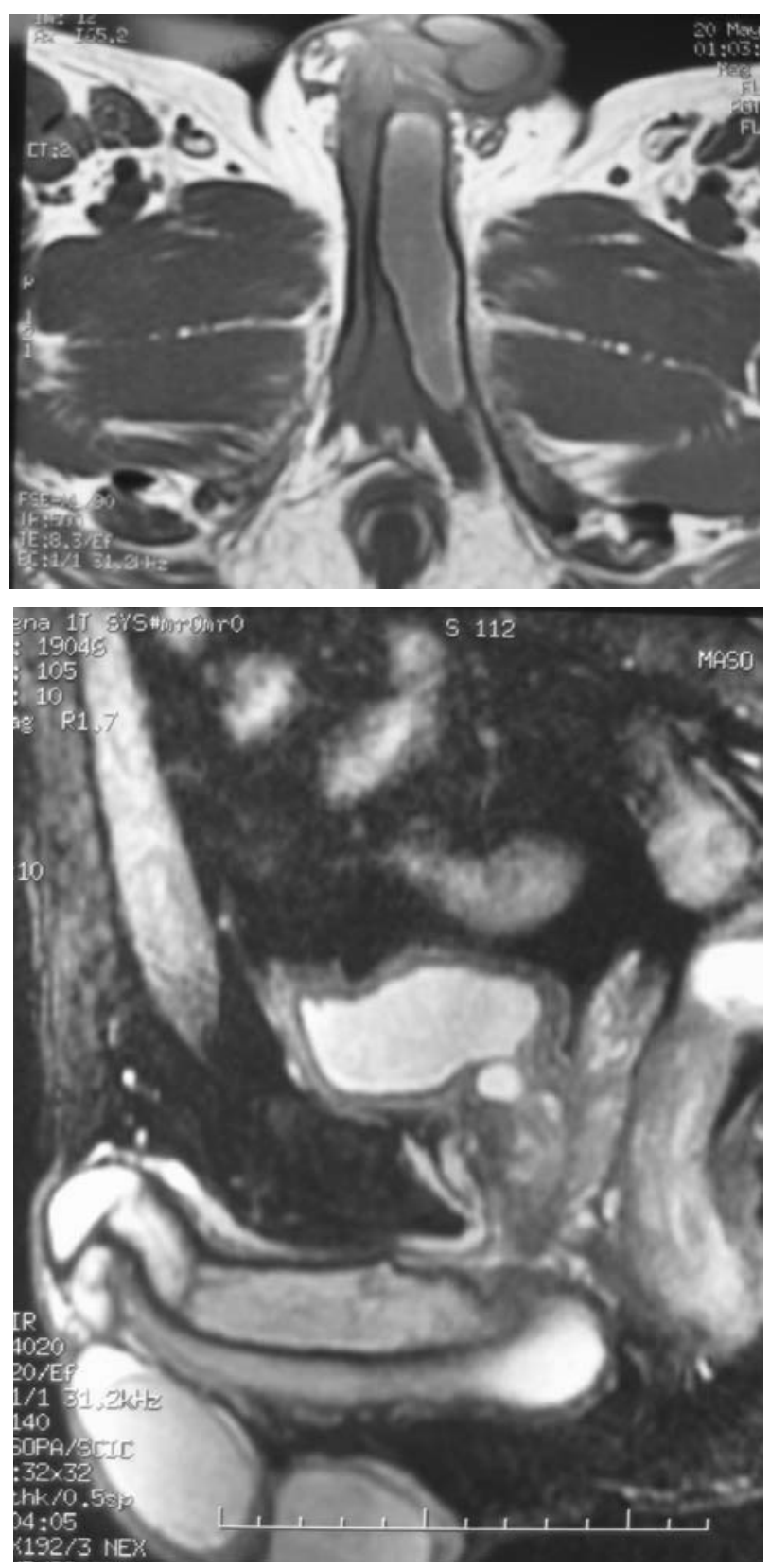

FIGURAS 1 y 2. RMN de pene

\section{DISCUSIÓN}

La irrigación arterial del pene depende de las arterias pudendas internas (ramas de las hipogástricas) que a su salida del periné se dividen en tres ramas: bulbouretral, dorsal del pene y cavernosa. Los entramados plexos venosos confluyen en la vena dorsal profunda, en la vena bulbar y la cavernosa. Finalmente existe un sistema venoso superficial que transcurre por encima de la fascia de Buck y que drena a través de vasos únicos o múltiples la sangre de las cubiertas peneanas (sin implicación en el mecanismo de la erección) hacia los territorios safeno, femoral y epigástrico.

La ruptura, espontánea o no, de una de estas vénulas podría explicar la formación de un hematoma perineal sin otra clínica acompañante.

Este tipo de tumoración se presenta de forma silente frente a la clínica típica de la fractura peneana: chasquido, dolor intenso, detumescencia brusca, hematoma y deformidad concomitante ${ }^{3}$. Los traumatismos genitales son los responsables de cerca del $40 \%$ de los casos, asociando lesiones más graves y mayor frecuencia de rotura uretral ${ }^{4}$.

La ruptura de vénulas del sistema venoso superficial podría explicarse por microtraumatismos repetidos y/o alteraciones del endotelio vascular, sin necesidad de agente traumático notorio. La propia localización anatómica concreta y autolimita la expansión del hematoma.

Tras el examen clínico, el diagnostico más fiable se obtiene mediante Resonancia Magnética Nuclear ${ }^{5,6}$ ya que permite establecer la integridad de la albugínea, lo que será fundamental de cara a plantear o no una exploración quirúrgica ${ }^{7}$. También permite el diagnóstico diferencial con tumoraciones derivadas de partes blandas como en el caso descrito.

En este paciente, el tratamiento conservador (con antiinflamatorios, antiagregantes y frío local) fue el de elección.

\section{REFERENCIAS}

1. Rubio Briones J, Sánchez Martín F, Segura Paños A, Regalado Pareja R, Caffaratti Sfullini J, Ruiz-Castañé E, et al. Tratamiento quirúrgico de la fractura de los cuerpos cavernosos y uretra:Revisión de la literatura a propósito de dos casos. Arch Esp de Urol. 1996;49(5):499-506.

2. El-Sherif AE, Dauleh M, Allowneh N,Vijayan P. Management of fracture of the penis in Qatar. Br J Urol. 1991;68(6):622-625.

3. Hafiani M, Bennani S, Debbagh A, El Mrini, M, Benjelloun S.Bilateral fracture of the corpus cavernosum with complete rupture of the urethra. J Urol (Paris). 1995;101(4):200-202.

4. Lema Grille J, Blanco Parra M, Cimadevila García A, Rodríguez Núñez H, Tato Rodríguez J, Cimadevila Covelo A. Fractura de pene con afectación de cuerpos cavernosos y uretra. Actas Urol Esp. 1999;23(10):900-903.

5. Vera Donoso CD, Vidal J, Garcia Revoll L, Boronat Tormo F, Ruiz Cerda JL, Jiménez Cruz JF. Diagnostico y Tratamiento del traumatismo peneano coital. Actas Urol Esp. 1991;15(4):397-400.

6. De Lucchi R, Rizzo L, Rubino A, Tola E. Magnetic Resonante diagnosis of traumatic penile fracture. Radiol Med (Torino). 2004;107(3):234-240.

7. El Taher AM, Aboul-Ella HA, Sabed MA, Gaafar AA. Management of penile fracture. J Trauma. 2004;56(5):1138-1140;discussion 1140.

Correspondencia autor: Dr. R.H. Martínez-Rodríguez

Servicio de Urología. Fundación Puigvert.

Cartagena, 340-350 - 08025 Barcelona. Tel.: 934169700

E-mail autor: dr.rmartinez@yahoo.es

Información artículo: Nota clínica

Trabajo recibido: mayo 2006

Trabajo aceptado: diciembre 2006 